\title{
Discussion on the Role of NGO from the Perspective of Participatory Governance-Study on "Community Service Management by Project in Qingyan Street, Daxing District, Beijing"
}

\author{
Long Fei \\ Department of Public Administration, Beijing Institute of Petrochemical Technology, China
}

Copyright (C2016 by authors, all rights reserved. Authors agree that this article remains permanently open access under the terms of the Creative Commons Attribution License 4.0 International License.

\begin{abstract}
This paper discusses the practice in "Community Service Management by Project in Qingyan Street, Daxing District, Beijing". It points out that: with the unique advantages of being professional, efficient and integrity, NGOs can play a part in the grassroots social governance in China that the government and market cannot play. It discusses the role of an NGO (Community Participation Service Center )plays in "Community Service Management by Project", that is: ideas updating, ability building and resource coordinating.
\end{abstract}

Keywords Community, NGO, Community Service Management

\section{Introduction}

NGO, short for Non-Governmental Organization, also known as Nonprofit Organization, the Third Sector, Civil Society Organization, first appeared in relevant documents of the United Nations. A non-governmental organization (NGO) is an organization that is found not for the purpose of making profit, falls in between the government and market, organizational, civil, nonprofit, self-governing and voluntary. With the economic and social transition since the reform and opening up, NGOs have played more and more prominent role in the course of urban governance in China especially in community governance. This article is to do a deep exploration of the positive role of a NGO plays from the perspective of participatory governance, based on the case study of "Community Service Management by Project in Qingyan Street, Daxing District, Beijing".

Since the reform and opening up, the relationship between the country and society has restructured, with the space for self-governance gradually expanding and the era dominated by the state and the government slowly entered into the one dominated by the market and the society. "Through institutional reform and innovation, the government guides the free flow and reasonable allocation of social resources, promotes a diversified development of the society and reduces the direct intervention to social life, providing favorable conditions and enough space for the growth and development of social forces. "The change of the relationship between the state and society also facilities the rise of NGOs and accelerates the transformation of social governance model, which leads to the reorganization of participatory governance.

The so-called "Participatory Governance" means that the government, market and NGO become the main bodies of multi-governance that have irreplaceable and positive role respectively in the management of the state and society. Beyond market, the government and NGOs cooperate together to accomplish the task of social management with a common goal. The main feature of this model is that: the government will transfer or authorize part of its power to NGOs so that they can obtain legitimacy and some degree of autonomy in social governance. When it comes to the participatory governance in community level, what matters is the effective participation of residents in a community, but the effective participation largely depends on the role played by NGOs.

\section{Research at Home and Abroad}

"The core of participatory governance relies in civic participation in social governance. Civic participation means a form of using civil rights, a redistribution of power, which enables the views of citizens who are unable to grasp the power in political and economic activities to be considered in the future plan. "Civic participation is a kind 
of political activity in which citizens in the course of urban development and management directly or indirectly affect the process of social governance via a certain way and method, so that the interest of their own, specific groups or the public can be achieved. The main body of civic participation is individual citizens or social organizations. The focus of participation is to make positive influences to the government's decision making process of public policy; the aim is to make contributions to the achievement of specific interests. Civic participation of urban governance should include participation in discovering problems, participation in decision-making, participation in the implementation and supervision, which can be said a real sense of community participation of participatory governance, because it is the process in which citizens voluntarily participate in social affairs management in a state of purposeful, conscious, organized and well-planned, to find problems, make decisions, develop plans, implement and complete, and provide evaluation in the end, which all require the participated citizens to possess subject consciousness, enthusiasm and wisdom.

On the role of NGOs in the social governance, foreign scholars have done in-depth research from the angle of corporatism, modern governance theory and the third party governance theory. They pointed out that NGOs can participate in the grass-root governance via co-governance mode, which is helpful to make up for the defects of government management. Caner B Mueller pointed out that the main value of civil society relies in its basic functional dimension, namely defensive dimension, legalization dimension, participation dimension and integration dimension. ${ }^{[1]}$ Based on China's national conditions, domestic scholars analyzed the role that NGOs play in the management of urban and community governance. Dou Zexiu pointed out that modern urban governance advocates that NGOs should be seen as the important partners of the government in the course of urban governance, in which NGOs will participate in all the propositions that the government advocates, and NGOs will serve as the following: firstly, it helps to coordinate social relation of interests, resolve conflicts and maintain the stability and order of the community; secondly, it helps to encourage residents to participate in a right order, promote the construction of community democracy; thirdly, it meets citizens' need for diversification, improve the quality of community service; fourthly, it helps to shape community culture, promoting the construction of community spiritual civilization. [2] Song Shiping, Li Jianchun and others analyzed the social function of NGOs, thinking that the role of NGOs in community governance is mainly reflected in the following aspects: an important channel for citizens to express their interests, and an important bridge between the government and the citizen to communicate and interact; NGOs are micro foundation of the grass-roots society, promoting the democratization of governance and also improving the effectiveness and legitimacy of governance; NGOs are the major force in the construction of democratic politics; NGOs are the important resource for social management innovation, and they play an significant role in both constructing harmonious society and crisis management. ${ }^{[3]}$

Concerning research on the relationship between government and non-governmental organizations, American scholar Robert Alan Dahl ${ }^{[4]}$ thinks that the way of allocating political resources has direct impact on the governance boundary of government public authority. In traditional agricultural society, political resources are scattered with "accumulation-concentration", where government is the core power of public affairs governance; while in modern industrial society, political resources are distributed with "dispersion-radiation", where non-governmental organizations can occupy a place in allocating political resources and are "key participators". Chinese scholar Kang Xiaoguang ${ }^{[5]}$ discusses government management and way of controlling non-governmental organizations through concepts of "administrative absorption of society" and "classification control". Su Dalin $^{[6]}$ points out that positive interaction between government and non-governmental organizations is mainly based on the following factors: both have common value concepts, complementary governance functions and a long history of cooperation. Chen Xiaoji ${ }^{[7]}$ thinks that "conflict paradigm" is the mode between government and non-governmental organizations in the traditional public administration. The relationship between government and non-governmental organizations is regarded as a competitive relation, which in essence conflicts with each other, thus constituting typical "conflict paradigm". Pang Xiaoning ${ }^{[8]}$ compares traditional government-led mode with self-government mode in community development. They point out that community self-government mode emphasizes delegation of power, in which non-governmental organizations and community voluntary organizations are the backbone power of community development; while government mode gives more emphasis to its service and construction function

\section{Major Practice in "Community Service Management by Project in Qingyan Street, Daxing District, Beijing"}

Located in the north of Daxing new town and established when transforming county into urban district in 2002, Qingyan Street, Daxing District, Beijing, now has twenty-eight communities in total, covering an area of 30 square kilometers and a resident population of 1.3 million. In June 2007, the community service center was responsible for the Qingyuan Street, beginning to try to carry out management by projects with different communities as pilots. In 2008, a special team was set up for Qingyuan Street to carry out "Participation Community Service 
Management by Project", with over 70 million Yuan been invested successively. In "Participatory Community Service Management by Project", the traditional top-to-down model of community service will be transformed into an project model in which vulnerable groups will be paid attention to, the needs of residents will be valued, the characteristics of community will be combined, and the residents will participate in providing services. The Street provided financial support for the project, neighborhood committee gave coordination and all the residents participated independently all the way. The "community project" actually refers to a series of relevant activities implemented for the purpose of resolving the needs from the community. This kind of activity that is organized and carried out by the community has certain goals and restrictions for resource cost. Specific practice is:

\subsection{Carry out Capacity-building Training}

In order to help people understand the participatory concept and grasp working methods related to it, the sub-district office with the support of Beijing Community Participation and Action Center has hold many activities on the project knowledge, the concept and methods for different bodies like the government functionary, community staff and residents. In addition, they also organized other kind of activities including visit, expedition and communication to broaden their way-of-working and way-of-thinking, using the participatory method they learned in practice.

\subsection{Introduce Multi-governance Body}

In order to work smoothly and orderly, Qingyuan Street established a leading group consisting of the leaders of both sub-district office and service center of community participation management. This leading group served as the top governing body of community participation service management by project. It also set up a supervision group that was composed of discipline inspection sector, people's congress and financial office to monitor projects selection and audit the use of funds. What's more, Qingyuan Street set up a special team that was composed of the staff of community service center and service center of community participation management, which was the body dealing with daily affairs. It also set up a project executive team including community committee, resident representatives and volunteers as the main body to implement projects. Within this kind of governing structure, sub-district office and the NGO, service center of community participation management, jointly constituted the leading group, the supervision group had sub-district office as the main body, and the working team also had both community service center and service center of community participation management. Furthermore, the resident representatives, volunteers together with the neighborhood committee constituted the main body of project implementation. It can be seen that the spirit of cooperative and panticipatory governance could be reflected in every governing unit of Participatory Community Service Management by Project, including its leading group, working team and executive group. It showed the philosophy that the government, NGOs and residents and other interested parties should cooperate and negotiate with each other for the goal of promoting the development of the community.

\section{The Role that NGO Plays}

\subsection{Introduction of Beijing Community Participation Service}

Beijing community participation service is a NGO designated to promoting participatory community service. It is also known as Beijing Canyushi Information Consultation Center, with Song Qinghua as its director. Community Participation Service Center(CPSC) was established in December 2002, and business registration was proceed in September 2003. In February 2009, the organization was registered officially as a private non-profit organization in the Civil Affairs Bureau of Dongcheng District city in Beijing. Its commission is to promote sustainable participatory governance and build harmonious community through advocating the idea and practice of community participation. It sees equity, justice, respect and cooperation as its values.

\subsection{The role that Community Participation Service Center Plays}

\subsubsection{Ideas Updating}

One of the key factors of success in participatory governance of Qingyuan Street is the awareness of residents' active participation. According to Director Zhang Yufang: "The residents didn't want to apply for any project in the beginning stage. They thought that the community affairs had nothing to do with themselves. The government should be responsible for the community." Song Qinghua, director of CPSC, made great efforts to change their minds.

At Kanglongyuan community, for example, Song had several meetings with the residents. During the meetings, Song told them over and over again that the main force of community construction was not any others but themselves. A resident told me: "Thanks to the training of director Song, We realized that we are not only community residents, we are also participants and organizers of community affairs." As a partner, the service center showed great enthusiasm and provided great support for participatory service management by project in Qingyuan Street without charging any fees or only charging a little. The two parties kept a very close relationship, with so frequent communication and smooth cooperation that the Director Zhang Yufang emphasized again and again that the CPSC helped her a lot. She also said that their participatory service management by project could not succeed without 
the help of the community participation service center.

\subsubsection{Ability Building}

The priority among priorities in community participation service center is to conduct training on ability building, which will be very important and be implemented frequently in the first three years of the project. According to relevant data and interview, the complete plan on the training was designed and implemented by the community participation service center, while the community service center of the Street was responsible for organize, that is to call the staff at neighborhood committee and the residents together to participate in the training. The training contained two stages. The first referred to the preparation stage, in which the content of the training covered what is community participation, how it is carried out, how to manage the community service project, how to cultivate and develop the community organizations, and how to executive a community service project plus how to innovate community services and etc. Director Zhang Yufang told me: "Their main job is to help us to train. They help us to train our community workers; they help us to train our community residents. They taught us how to hold an open space conference, that we can let the participants to express their views and finally form an ideal meeting result. We used to have a meeting to waste a long time but it was difficult to reach a consensus." A resident the author interviewed also said: "Director Song helps us a lot! We didn't know how to have a meeting effectively before. We were tired up in a meeting all day, but we couldn't achieve any result! Now we have learned how to have a meeting."

The second one was the stage about training on project management that the project was executive. The CPSC would give the execution team of project trainings on the knowledge about managing a project and project implementation. In Short, it can be said that the content was very comprehensive that covered nearly all aspects of participatory community service management by project, but did it work? The conversation with Director Zhang Yufang and the residents revealed that the training worked very well indeed, since the training was very suitable to actual circumstances of domestic communities, useful, practical and forward-looking.

\subsubsection{Resource Coordinating}

Besides the above two roles, community participation service center has another role that can easily be ignored, that is to help the community applying for a project to obtain external resources and support. In fact, the success of participatory community service management by project cannot do without a great amount of capital.

The author noted from the case of "Green island life museum" at Kanglongyuan Community that the "Green island life museum" got a strong support in finance from a NGO named Vantone Foundation, which should be attributed to the community participation service center acting as a go-between to a large extent. As a matter of fact, it is another important role for NGOs to help communities seek more resources outside the government and community, serve as a bridge between the government and NGOs, between residents and NGOs, between residents and the society.

\section{Conclusions}

With the unique advantages of being professional, efficient and integrity, NGOs can play a part in the grassroots social governance in China that the government and market cannot play. Therefore, it will be a long-term task for the government to selectively absorb some NGOs to participate in community management, letting them to play their important role.

\section{REFERENCES}

[1] Cornell·B·muller, The contemporary discourse analysis on civic society and national relationship, quoted from Editor-in-Chief named He Zeng, "Civic society and governance" by Social Sciences Literature Press, first edition in May 2011, page 14-15

[2] Dou Zexiu and others, "Urban governance in transformation" by Social

[3] Sciences Literature Press, first edition in October 2010, page 6-8

[4] Song Shiping, Li Jianchun and others, "Study on NGO and rural social

[5] governance" by Central University for Nationalities Press, first edition in September 2012, page 42-59

[6] Robert Alan Dahl, Modern Political Analysis, translated by Wang Huning, Shanghai Translation Publishing House, 1987]Kang Xiaoguang, Administrative Absorption of Society, quoted in Research on Frontier Issues of Non-profit Organizations by Lu Xianying and Han Heng, Zhengzhou University Press, January 2010, version 1, page4-20.

[7] $\mathrm{Su}$ Dalin, Towards Positive Interaction: Discussion on cooperative relationship between government and non-governmental organizations, Gansu Social Sciences, 2006(6)

[8] Chen Xiaoji, From "conflict paradigm" to "cooperation paradigm”, Inner Mongolia Social Sciences, 2007(7)

[9] Pang Xiaoning, Jia Xinjie, Urban Community Governance: from government-led mode to cooperative self-governance, Future and Development, 2013(12) 